\title{
Electron Ionization (EI) Mass Spectra of Exo-Endo Double-Bond Isomers of Polycyano "Push-Pull" Pentadienes Derived from Cycloalkylidene Malonic Acid Derivatives
}

\author{
Kalevi Pihlaja, Vladimir V. Ovcharenko, and Pentti Oksman* \\ Department of Chemistry, University of Turku, Turku, Finland \\ Erich Kleinpeter and Jochen Woller \\ Institute für Organische Chemie und Strukturanalytik, Universität Potsdam, Golm, Germany
}

The title compounds, which exist in solutions as mixtures of exo/endo double bond isomers due to the "push-pull" effect of the electron-donating and electron-withdrawing substituents, were studied by mass-spectrometric methods. Their fragmentation routes under electron impact were established and confirmed by metastable ion analysis and accurate mass measurements. The results demonstrated that the relative amounts of exo/endo isomeric molecular ions are in close agreement with the isomeric ratios observed in solutions by the NMR, although the mass spectra of the tetracyano derivatives indicated a small fraction of molecular ions existing in the endo form, which could not be detected in solution by the NMR methods. (J Am Soc Mass Spectrom 2003, 14, 189-194) (c) 2003 American Society for Mass Spectrometry

$\mathrm{R}$ ecently, a number of polycyano pentadienes 1-17 (Scheme 1) were synthesized starting from cycloalkylidene malonitriles (or malonic esters) [1]. These products were found to exist as mixtures of exo/endo double-bond isomers [2, 3]. Their isomerism and conformational equilibria were studied experimentally by ${ }^{1} \mathrm{H}$ and ${ }^{13} \mathrm{C}$ NMR spectroscopy [2] and also investigated by ab initio calculations [3]. The exo/endo isomerism of Compounds 1-17 was found to be a function of the cycloalkyl ring size, of the nature of substituents, and of the degree of the "push-pull" effect ( $\pi$-polarization of the double bond). Thus, only the exo isomers could be detected in the case of the tetracyano compounds $\left(R=R^{\prime}=C N\right.$, Scheme 1$)$ regardless of the cycloalkyl ring size, whereas the ester derivatives exist in solutions as mixtures of exo/endo isomers, the endo structures being strongly preferred in the compounds containing seven- and eight-membered rings. The substitition pattern also plays an important role, so that the ester derivatives $\left(\mathrm{R}^{\prime}=\mathrm{COOMe}\right.$ or $\left.\mathrm{COOEt}\right)$ exist as pure endo isomers [2]. The phenomenon of sterically restricted rotation about the $\mathrm{C}-\mathrm{C}$ bond attaching the

Published online January 24, 2003

Address reprint requests to Dr. K. Pihlaja, Department of Chemistry, University of Turku, FIN-20014 Turku, Finland. E-mail: kpihlaja@utu.fi

*Present address: Department of Chemistry, POB 3000, FIN-90014 University of Oulu, Finland. 1-(methylthio)vinyl substituent was also revealed by the NMR study [2]. The relative stabilities of the exo/ endo isomers as determined from ab initio calculations [3] were in agreement with the experimental data (the calculated stabilities of the endo isomers increased with the cycloalkyl ring size, beginning from six-membered derivatives). The theoretical analysis has further clarified the conformational preferences (regarding s-cis/strans conformers) and demonstrated the presence of the so-called "allylic strain" between the vicinal substituents in the six-membered exo isomers. In general, Compounds 1-17 are characterized in solutions by various structural features including the valence (exo/endo) and geometrical $(E / Z)$ isomerism and conformational equilibria.

From the viewpoint of organic mass spectrometry, "push-pull" olefins comprising both electron-donating and electron-accepting functional groups can serve as model compounds for studying the effects of valence isomerization (such as double-bond shifts and hydrogen atom migrations) on the mass-spectrometric fragmentation patterns.

A literature survey shows that some peculiar fragmentation patterns have previously been observed in polycyano olefins which bear resemblance to Compounds 1-17. Note that the simultaneous presence of electron-donating and electron-accepting functional groups within a saturated hydrocarbon backbone does 

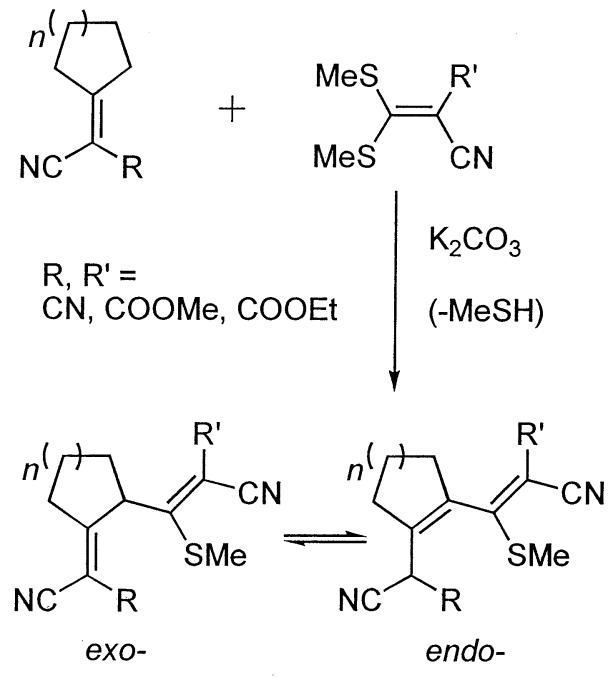

$1-17$

Scheme 1. Synthesis and isomeric structures of Compounds 1-17.

not necessarily produce unusual fragmentations. Thus, the EI mass spectra of $\alpha$-methylthio- $\omega$-nitriles, MeS$\left(\mathrm{CH}_{2}\right)_{n}-\mathrm{CN}$, are dominated by rather unexceptional peaks of $\mathrm{MeS}^{+}=\mathrm{CH}_{2}$ and $\left[\mathrm{M}-\mathrm{CH}_{3} \mathrm{~S}\right]^{+}$ions [4]. On the other hand, the EI and CI mass spectrometry of the dicyanomethylene derivatives of benzophenone and 9-fluorenone (Scheme 2) studied by Watson and coworkers $[5,6]$ revealed a complex rearrangement (involving migrations of two $\mathrm{H}$ atoms) of the $\mathrm{M}^{+\cdot}$ ions produced from the benzophenone derivative, which resulted in the formation of stable $\left[\mathrm{M}-\mathrm{CH}(\mathrm{CN})_{2}\right]^{+}$

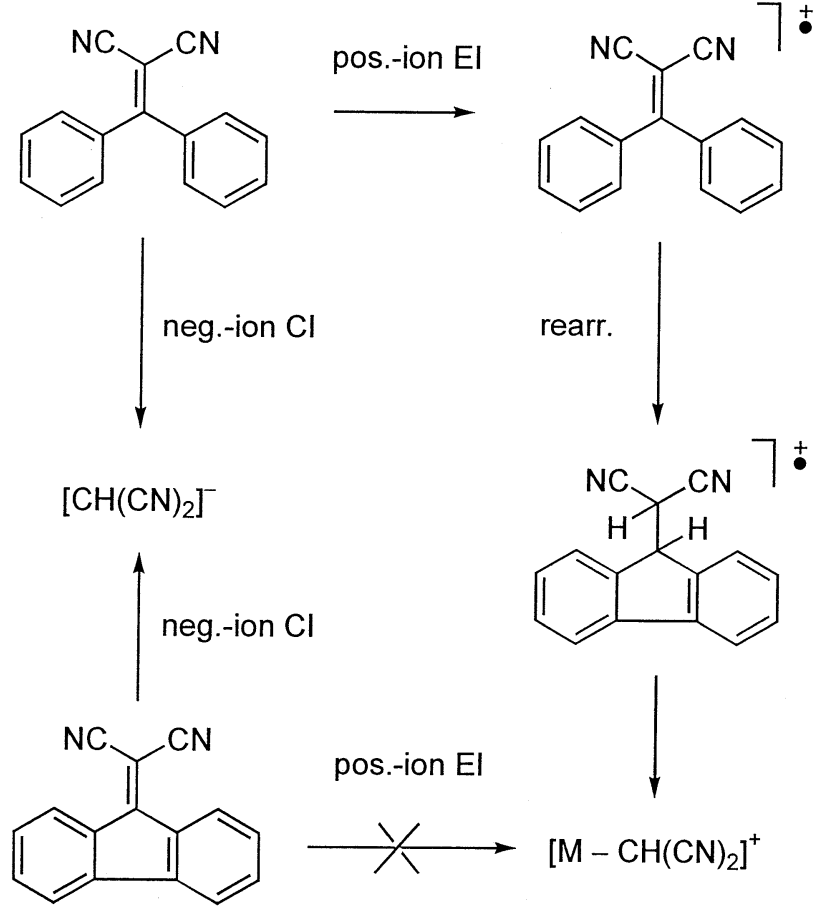

Scheme 2. Mass-spectrometric behavior of dicyanomethylene derivatives of benzophenone and 9-fluorenone $[5,6]$. ions under EI conditions [5]. Under negative-ion CI conditions [6], the addition of a hydrogen atom at the dicyanomethylene group prior to electron capture led to the formation of malodinitrile anions from both the benzophenone and 9-fluorenone derivatives:

$$
\mathrm{M} \stackrel{\mathrm{H}^{\cdot}}{\longrightarrow}[\mathrm{MH}]^{\cdot} \stackrel{e^{-}}{\longrightarrow}[\mathrm{MH}]^{-} \longrightarrow\left[\mathrm{CH}(\mathrm{CN})_{2}\right]^{-}
$$

\section{(cf. Scheme 2 for the M structures)}

Similarly, facile addition of $\mathrm{H}^{\cdot}$ to tetracyanoquinodimethane (TCNQ) prior to ionization was observed in TCNQ salts and charge-transfer complexes under EI conditions [7].

The main objective of our present work is to study the fragmentations of Compounds 1-17 following electron ionization (EI) and to identify possible effects of their structural transformations in solutions (e.g., of the exo/endo isomerism) on the fragmentation patterns.

\section{Experimental}

The purity and structure of Compounds 1-17 were confirmed by ${ }^{1} \mathrm{H}$ and ${ }^{13} \mathrm{C}$ NMR (see [1, 2]). In fact it should be mentioned that two compounds (not included here; numbered in reference [2] as $2\{n=3$, endo $\}$ and $3\{n=3$, endo $\}$ ) which were proved erroneous by both NMR and mass spectra were included in [2] by accident.

The mass spectra were recorded on an upgraded VG $7070 \mathrm{E}$ and on a VG ZABSpec-oaTOF mass spectrometers both running OPUS software (Manchester, UK). Samples were introduced using water-cooled direct insertion probe at temperatures between ambient and $500 \mathrm{~K}$. The ionization energy of $70 \mathrm{eV}$ and trap currents of $100 \mu \mathrm{A}(7070 \mathrm{E})$ and $200 \mu \mathrm{A}$ (ZABSpec) were used for creating positive ions by EI.

The basic spectra were obtained at a resolving power of 1000 on VG 7070E. The accurate mass measurements were performed at a resolving power of 5000 (or, when needed, at 10,000) using either peak matching or accurate mass calibration methods. The daughter ions spectra were obtained at a precursor ion resolving power of 5000. The MIKE spectra were obtained of selected precursors using air as collision gas at the transmission level of $50 \%$. In all cases PFK was used as the reference compound.

\section{Results and Discussion}

The molecular stability of the investigated compounds under electron ionization largely varies (Table $1 \mathrm{a}-\mathrm{c}$ ). When the substituents $R$ and $R^{\prime}$ are both cyano groups (Compounds 1-4) the base peaks correspond to $\mathrm{M}^{+\cdot}$ ions regardless of the size of the cycloalkene ring. The replacement of one or two of the substituents by a carboxylic ester group increases the number of available 
Table 1a. Principal ions (\% of the relative abundance, RA) in the EI mass spectra of Compounds 1-17 $(\mathbf{A}=\mathrm{RCHR}$, see Scheme 1) and the relative contributions of the exo and endo forms (indicated as number of stars)

\begin{tabular}{lcccccccccc}
\hline Compound & $n$ & $\mathrm{R}$ & $\mathrm{R}^{\prime}$ & $\mathrm{M}^{+\cdot}$ & {$\left[\mathrm{M}-\mathrm{CH}_{3}\right]^{+}$} & {$\left[\mathrm{M}-\mathrm{CH}_{3} \mathrm{~S}\right]^{+}$} & {$[\mathrm{M}-\mathrm{A}]^{+}$} & {$[\mathrm{M}-\mathrm{CN}]^{+}$} & endo & exo \\
\hline \hline $\mathbf{1}$ & 1 & $\mathrm{CN}$ & $\mathrm{CN}$ & $254(100)$ & $239(25)$ & $207(58)$ & $(-)$ & $228(62)$ & $\left.* *)^{*}\right)$ \\
$\mathbf{2}$ & 2 & $\mathrm{CN}$ & $\mathrm{CN}$ & $268(100)$ & $253(33)$ & $221(55)$ & $203(3)$ & $242(44)$ & $* * * * *$ \\
$\mathbf{3}$ & 3 & $\mathrm{CN}$ & $\mathrm{CN}$ & $282(100)$ & $267(75)$ & $235(90)$ & $217(13)$ & $256(4)$ & $* *$ & $* * * *$ \\
$\mathbf{4}$ & 4 & $\mathrm{CN}$ & $\mathrm{CN}$ & $296(100)$ & $281(58)$ & $249(95)$ & $231(22)$ & $270(11)$ & $* *$ & $* * * *$ \\
\hline
\end{tabular}

Table 1b.

\begin{tabular}{|c|c|c|c|c|c|c|c|c|c|c|c|c|}
\hline Compound & $n$ & $\mathrm{R}$ & $R^{\prime}$ & $\mathrm{M}^{+\cdot}$ & $\begin{array}{l}{[\mathrm{M}-} \\
\mathrm{Me}^{+}\end{array}$ & $\begin{array}{c}{[\mathrm{M}-} \\
\mathrm{MeS}]^{+} \\
\end{array}$ & $\begin{array}{c}{\left[\mathrm{M}-\mathrm{COOR}^{\prime \prime}\right]^{+}} \\
\mathrm{R}^{\prime \prime}=\mathrm{Me}, \mathrm{Et}\end{array}$ & {$[\mathrm{M}-\mathrm{A}]^{+}$} & $\begin{array}{c}{[\mathrm{M}-} \\
\left.\mathrm{COOC}_{2} \mathrm{H}_{4}\right]^{+\cdot}\end{array}$ & $\begin{array}{c}{[\mathrm{M}-} \\
\left.\mathrm{COOC}_{3} \mathrm{H}_{7}\right]^{+}\end{array}$ & endo & exo \\
\hline 5 & 2 & $\mathrm{CO}_{2} \mathrm{Me}$ & $\mathrm{CN}$ & $301(100)$ & $286(13)$ & 254 (57) & $242(74)$ & $203(47)$ & $(-)$ & $(-)$ & $* * *$ & $* * *$ \\
\hline 6 & 4 & $\mathrm{CO}_{2} \mathrm{Me}$ & $\mathrm{CN}$ & $329(48)$ & $314(12)$ & 282 (34) & $270(42)$ & $231(100)$ & $(-)$ & $(-)$ & $* * * *$ & $* *$ \\
\hline 7 & 1 & $\mathrm{CO}_{2} \mathrm{Et}$ & $\mathrm{CN}$ & 301 (64) & $(-)$ & 254 (14) & 228 (49) & $189(-)$ & $229(51)$ & $214(100)$ & $*$ & $* * * * *$ \\
\hline 8 & 2 & $\mathrm{CO}_{2} \mathrm{Et}$ & $\mathrm{CN}$ & 315 (91) & $300(4)$ & $268(16)$ & $242(44)$ & $203(41)$ & $243(45)$ & $228(100)$ & $* *$ & $* * * *$ \\
\hline 9 & 3 & $\mathrm{CO}_{2} \mathrm{Et}$ & $\mathrm{CN}$ & $329(44)$ & $314(5)$ & $282(12)$ & $256(72)$ & $217(73)$ & $257(34)$ & $242(66)$ & $* * * * *$ & * \\
\hline 10 & 4 & $\mathrm{CO}_{2} \mathrm{Et}$ & $\mathrm{CN}$ & $343(28)$ & $328(4)$ & 296 (13) & $270(37)$ & $231(71)$ & 271 (25) & $256(34)$ & $* * * *$ & $* *$ \\
\hline 11 & 1 & $\mathrm{CN}$ & $\mathrm{CO}_{2} \mathrm{Me}$ & $287(46)$ & $(-)$ & $(-)$ & $228(100)$ & $(-)$ & $(-)$ & $(-)$ & & $* * * *$ \\
\hline 12 & 2 & $\mathrm{CN}$ & $\mathrm{CO}_{2} \mathrm{Et}$ & 315 (37) & $300(1)$ & $268(<1)$ & $242(100)$ & $(-)$ & $243(73)$ & $228(30)$ & & $* * * * *$ \\
\hline
\end{tabular}

Table 1c.

\begin{tabular}{|c|c|c|c|c|c|c|c|c|c|}
\hline Compound & $n$ & $\mathrm{R}$ & $\mathrm{R}^{\prime}$ & $\mathrm{M}^{+\cdot}$ & {$\left[\mathrm{M}-\mathrm{CH}_{3} \mathrm{~S}\right]^{+}$} & {$\left[\mathrm{M}-\mathrm{CH}_{3} \mathrm{~S}-\mathrm{C}_{2} \mathrm{H}_{4}\right]^{+}$} & {$[\mathrm{M}-\mathrm{A}]^{+}$} & endo & exo \\
\hline 13 & 1 & $\mathrm{CO}_{2} \mathrm{Et}$ & $\mathrm{CO}_{2} \mathrm{Me}$ & $334(7)$ & $287(3)$ & $259(7)$ & $222(100)$ & $* * * * * *$ & \\
\hline 14 & 3 & $\mathrm{CO}_{2} \mathrm{Et}$ & $\mathrm{CO}_{2} \mathrm{Me}$ & 362 (1) & $315(8)$ & $287(12)$ & $250(100)$ & $* * * * * *$ & \\
\hline 15 & 4 & $\mathrm{CO}_{2} \mathrm{Et}$ & $\mathrm{CO}_{2} \mathrm{Me}$ & $376(2)$ & $329(18)$ & $301(20)$ & $264(100)$ & $* * * * * *$ & \\
\hline 16 & 1 & $\mathrm{CO}_{2} \mathrm{Me}$ & $\mathrm{CO}_{2} \mathrm{Et}$ & $334(6)$ & $287(6)$ & $(-)$ & $236(100)$ & $* * * * *$ & $*$ \\
\hline 17 & 4 & $\mathrm{CO}_{2} \mathrm{Me}$ & $\mathrm{CO}_{2} \mathrm{Et}$ & $376(2)$ & 329 (94) & $(-)$ & $278(100)$ & $* * * * *$ & * \\
\hline
\end{tabular}

fragmentation channels, and the molecular ion stability is generally reduced, especially in the diesters 13-17 (Table 1c).

Most important fragmentation routes include the loss of $\mathrm{MeS}^{*}$ and $\mathrm{R}^{-} \mathrm{CH}^{-}-\mathrm{CN}$ (A) radicals from the $\mathrm{M}^{+\cdot}$ ions. The loss of $\mathrm{MeS}^{\circ}$ is understandably more prominent in the tetracyano derivatives 1-4, since the enthalpy of formation of MeS' (ca. $125 \mathrm{~kJ} / \mathrm{mol}$ ) is by $>300$ $\mathrm{kJ} / \mathrm{mol}$ higher than that of an ester group, COOR. It is seen from Table $1 \mathrm{~b}$ that $[\mathrm{M}-\mathrm{MeS}]^{+}$ions are invariably of a lower abundance than $[\mathrm{M}-\mathrm{COOR}]^{+}$. Apparently for the similar thermochemical reasons, $[\mathrm{M}-\mathrm{CN}]^{+}$ ions are only prominent in the absence of ester groups (Compounds 1-4). In the two extreme cases, when the formation of $[\mathrm{M}-\mathrm{MeS}]^{+}$ions is either clearly favored (1-4) or disfavored (13-17) for thermochemical reasons, their abundance seems to increase with the cycloalkyl ring size (1-4) or, at least, reach the maximum values in the eight-membered derivatives ( $n=4$, Table $1 \mathrm{a}$ and $\mathrm{c}$ ).

The $[\mathrm{M}-\mathrm{A}]^{+}$ions can be produced either from the endo isomers, in which the $\mathrm{R}-\mathrm{CH}-\mathrm{CN}$ substituent is connected to the cycloalkyl ring by a single $\mathrm{C}-\mathrm{C}$ bond, or from the exo isomers if some hydrogen shifts (cf. the Introduction) or double-bond isomerization preceded the fragmentation. However, the observed abundances of these ions seem to be generally in accordance with the exo/endo ratios determined in solution. Based on this, it is possible to conclude that the exo/endo ratios existing prior to ionization are not significantly changed under electron ionization conditions.

Figure 1 shows a spectacular example of the difference between the mass spectra of two compounds that can be attributed to the exo/endo isomerism. The mass spectrum of Compound $\mathbf{1 3}$ is dominated by the peak of $[\mathrm{M}-\mathrm{A}]^{+}$ions, which is completely absent from the spectrum of $\mathbf{1 1}$.

The situation with the exo/endo isomerism of $\mathrm{M}^{+\cdot}$ ions clearly depends on the substitution pattern. Thus, the tetracyano derivatives 1-4, which strongly favor exo forms in solution, produce very low abundance for $[\mathrm{M}-\mathrm{A}]^{+}$ions. In the ester derivatives, there are abundant $[\mathrm{M}-\mathrm{CN}(\mathrm{CH}) \mathrm{R}]^{+}$ions which even give rise to the base peaks in the diesters 13-17, clearly indicative for the endo form. If only one of the cyano groups is replaced by an ester group, the share of the endo form indicated by the abundance of $[\mathrm{M}-\mathrm{A}]^{+}$ions increases with the size of the cycloalkyl ring (e.g., Compounds 7-10, Table 1b).

The fragmentation routes of the monoester derivatives 5-12 are the most diverse among the compounds studied. The base peaks correspond not only to the $\mathrm{M}^{+}$. and $[\mathrm{M}-\mathrm{A}]^{+}$ions, but also to $\left[\mathrm{M}-\mathrm{R}^{\prime}\right]^{+}$ions (Compounds 11-12, Table $1 \mathrm{~b}$ ) or to the peculiar [M $\left.\mathrm{COOC}_{3} \mathrm{H}_{7}\right]^{+}$ions, which, judging by the metastable ion spectra, are formed by consecutive losses of $\mathrm{COOC}_{2} \mathrm{H}_{4}$ and ${ }^{\circ} \mathrm{CH}_{3}$ from the $\mathrm{M}^{+}$. 


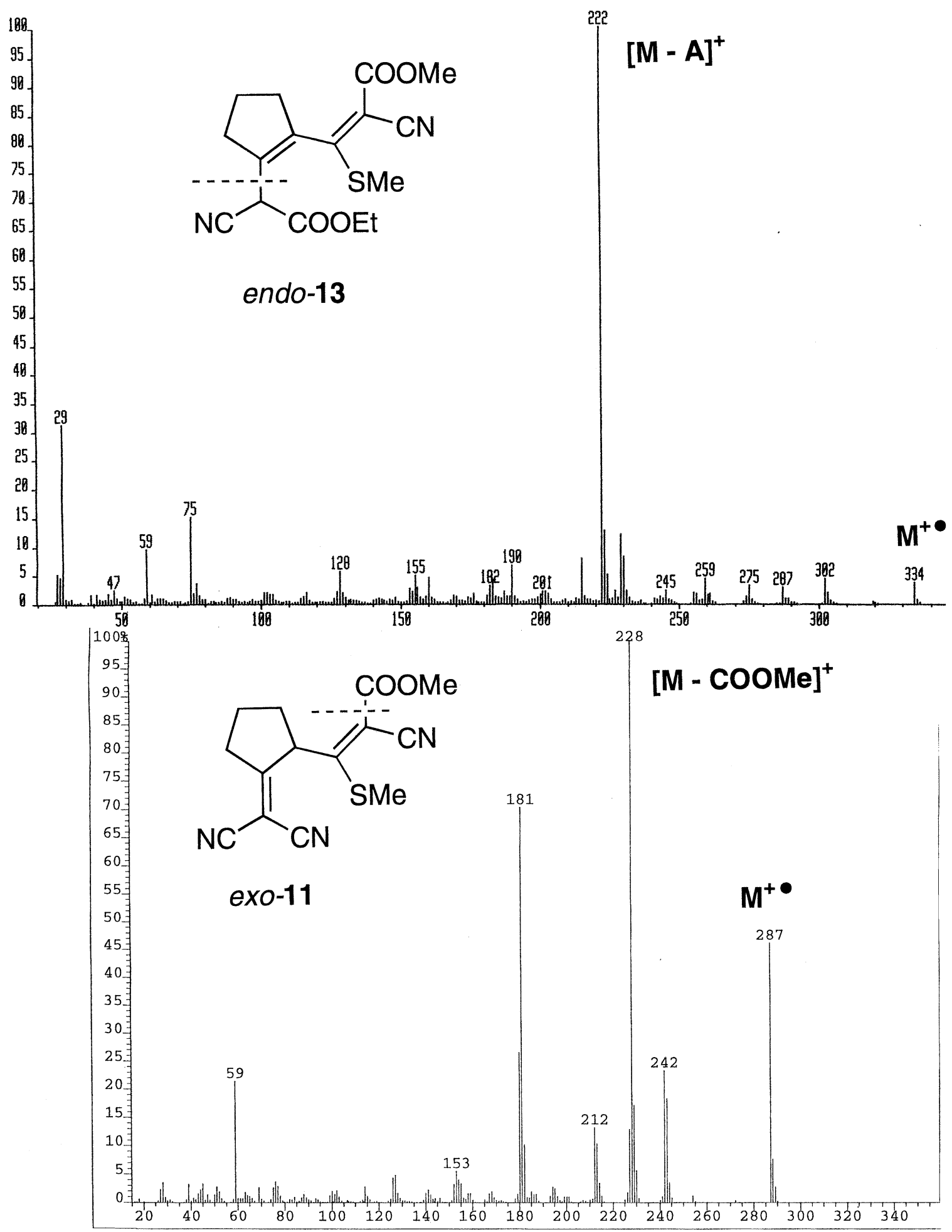

Figure 1. The 70-eV EI mass spectra of Compounds $\mathbf{1 1}$ and 13. The observed fragmentation patterns clearly indicate the predominant isomeric forms of the $\mathrm{M}^{+\cdot}$ ions. The $[\mathrm{M}-\mathrm{A}]^{+}$peak, which would have been located at $m / z 222$, is completely absent from the spectrum of $\mathbf{1 1}$.

The use of $[\mathrm{M}-\mathrm{A}]^{+}$ions for the evaluation of the exo/endo ratios in mono esters $\mathbf{5 - 1 2}$ is complicated by the specific fragmentations involving the ester function, such as the loss of $\mathrm{R}^{\prime \prime} \mathrm{OH}(\mathrm{MeOH}$ in $\mathbf{5}$ and $\mathbf{6}, \mathrm{EtOH}$ in $\mathbf{7}$, see Table 2). In some cases the $\left[\mathrm{M}-\mathrm{MeS}-\mathrm{R}^{\prime \prime} \mathrm{OH}\right]^{+}$ ions are even more abundant than $\left[\mathrm{M}-\mathrm{R}^{\prime \prime} \mathrm{OH}\right]^{+\cdot}($ Table 2). These fragmentations may reflect intramolecular cyclization of the $\mathrm{M}^{+\cdot}$ ions similar to the thermally induced cyclizations that have been previously described in push-pull alkenes bearing a pyrrole substitu- 
Table 2. Losses of neutral $\mathrm{MeOH}$ and EtOH during EI-induced fragmentation of the mono- and diester Compounds 5-17 ( $\mathrm{m} / \mathrm{z}$, \%RA)

\begin{tabular}{lccccc}
\hline & & & \multicolumn{3}{c}{$[\mathrm{M}-$} \\
Compound & $\mathrm{n}$ & $\mathrm{R}$ & \multicolumn{1}{c}{$\mathrm{R}^{\prime}$} & $\mathrm{MeOH}^{+\cdot}$ & {$\left[\mathrm{M}-\mathrm{EtOH}^{+}\right.$} \\
\hline \hline $\mathbf{5}$ & 2 & COOMe & $\mathrm{CN}$ & $269(15)$ & $(-)$ \\
$\mathbf{6}$ & 4 & COOMe & $\mathrm{CN}$ & $250(17)^{\mathrm{a}}$ & $(-)$ \\
$\mathbf{7}$ & 1 & COOEt & $\mathrm{CN}$ & $(-)$ & $255(27)$ \\
& & & & & $208(44)^{\mathrm{b}}$ \\
$\mathbf{8}$ & 2 & COOEt & $\mathrm{CN}$ & $(-)$ & $269(13)$ \\
$\mathbf{9}$ & 3 & COOEt & $\mathrm{CN}$ & $(-)$ & $236(15)^{\mathrm{b}}$ \\
$\mathbf{1 3}$ & 1 & COOEt & COOMe & $302(7)$ & $(-)$ \\
$\mathbf{1 6}$ & 1 & COOMe & COOEt & $(-)$ & $288(5)$ \\
$\mathbf{1 7}$ & 4 & COOMe & COOEt & $(-)$ & $330(21)$ \\
\hline
\end{tabular}

${ }^{\mathrm{a}}[\mathrm{M}-\mathrm{MeS}-\mathrm{MeOH}]^{+}$

${ }^{\mathrm{b}}[\mathrm{M}-\mathrm{MeS}-\mathrm{EtOH}]^{+}$

ent [8-10]. Depending on whether the compounds are derived from malonodinitrile $[8,9]$ or from cyanoacetic esters [10], their thermal cyclizations could involve the loss of $\mathrm{ROH}$ (Scheme 3). Since numerous analogies are known between the thermally induced intramolecular reactions and mass-spectrometric fragmentations, we assume this to be the case in Compounds 5-12 as well. Note that the loss of $\mathrm{ROH}$ in the case of diesters 13-17 occurs regiospecifically (Table 2), so that either $\mathrm{MeOH}$ or EtOH molecules are split off the $\mathrm{M}^{+\cdot}$ depending on whether $\mathrm{R}^{\prime}$ is COOMe or COOEt. The absence of $[\mathrm{M}-\mathrm{MeOH}]^{+\cdot}$ or $[\mathrm{M}-\mathrm{EtOH}]^{+\cdot}$ ions from the spectra of $\mathbf{1 4}$ and 15 (although each of these compounds has both the COOMe and COOEt groups) indicates that this fragmentation route is not only regiospecific, but also sensitive to the combined effect of such factors as the $\mathrm{M}^{+\cdot}$ stability, molecular geometry (cycloalkyl ring size and the nature of $R$ and $\left.R^{\prime}\right)$, and competition with other ester-directed fragmentations, such as the loss of $\mathrm{C}_{2} \mathrm{H}_{4}$ from $[\mathrm{M}-\mathrm{MeS}]^{+}$and $[\mathrm{M}-\mathrm{A}]^{+}$ions (see below). Another peculiar fragmentation related to the ester group produces $\left[\mathrm{M}-\mathrm{CO}_{2}\right]^{+\cdot}$ and $\left[\mathrm{M}-\mathrm{CO}_{2} \mathrm{H}\right]^{+}$ions, which are rather abundant (20 and $24 \% \mathrm{RA}$, respectively) in the spectrum of monoester 11. However, the loss of $\mathrm{COOH}$ is a unique occurrence among all the<smiles>[R5]C(=C(C#N)C#N)c1cc([R])c([R])[nH]1</smiles><smiles>[R]C(=O)/C(C#N)=C(/[R5])c1cc([R2])c([R])[nH]1</smiles>

Scheme 3. Thermally induced intramolecular cyclizations of pyrrole-substituted "push-pull" alkenes [8-10]. ester derivatives 5-17, and the loss of $\mathrm{CO}_{2}$ is only observed in two other compounds, 7and 12 (6 and 14\% RA, respectively).

The fragmentation leading to $[\mathrm{M}-\mathrm{Me}]^{+}$ions in the case of the methyl esters shows some regiospecificity with respect to the methoxycarbonyl group position: The $[\mathrm{M}-\mathrm{Me}]^{+}$ions are prominent in Compounds 5-6 $(\mathrm{R}=\mathrm{COOMe}, 12-13 \% \mathrm{RA})$, but not observed at all in Compound $11\left(\mathrm{R}^{\prime}=\right.$ COOMe). It is seen from Table $1 \mathrm{~b}$ that the $\left[\mathrm{M}-\mathrm{Me}^{+}\right.$abundances are widely variable in the spectra of the monoesters 5-12 (these ions are most abundant in compounds where $\mathrm{R}=\mathrm{COOMe}$ and $\mathrm{R}^{\prime}=$ $\mathrm{CN}$, but they are practically absent from the spectra of the diesters 13-17 even if $\mathrm{R}=$ COOMe.) Unlike the esters 5-17, there are rather abundant $\left[\mathrm{M}-\mathrm{Me}^{+}\right.$ions formed from the tetracyano derivatives 1-4 (Table 1a). In this case, they must necessarily originate from the cycloalkyl ring, which indicates that the fragmentation route involving the loss of $\mathrm{Me}$ from the cycloalkyl ring (as in 1-4) is suppressed by the ester-related fragmentations in $\mathbf{5 - 1 7 .}$

In general, fragmentations with the loss of hydrocarbon fragments are not very common in the mass spectra of 1-17. Two of the larger-ring tetracyano compounds (3 and 4) produce abundant ions at $\mathrm{m} / \mathrm{z} 228$ that correspond to $\left[\mathrm{M}-\mathrm{C}_{4} \mathrm{H}_{6}\right]^{+\cdot}(24 \% \mathrm{RA})$ and $[\mathrm{M}-$ $\left.\mathrm{C}_{5} \mathrm{H}_{8}\right]^{+\cdot}(61 \% \mathrm{RA})$ for 3 and 4 , respectively. The absence of ions at $m / z 228$ from the spectra of $\mathbf{1}$ and $\mathbf{2}$ may be due to the greater rigidity of the five- and six-membered rings precluding the hydrogen transfers that must be involved in the formation of unsaturated hydrocarbon fragments homologous to $\mathrm{C}_{4} \mathrm{H}_{6}$ and $\mathrm{C}_{5} \mathrm{H}_{8}$. The size of the cycloalkyl ring seems to be less important in the case of hydrocarbon losses that occur as secondary fragmentations. Thus, both the diesters $\mathbf{1 6}$ and $\mathbf{1 7}$ produce abundant $\left[\mathrm{M}-\mathrm{A}-\mathrm{C}_{2} \mathrm{H}_{4}\right]^{+}$ions (ca. 90\% RA). However, since the ethoxycarbonyl group $\mathrm{R}^{\prime}=\mathrm{COOEt}$ is preserved in the $[\mathrm{M}-\mathrm{A}]^{+}$ions formed from 16 and 17 , it is not clear whether the $\left[\mathrm{M}-\mathrm{A}-\mathrm{C}_{2} \mathrm{H}_{4}\right]^{+}$ions are formed in this case exclusively by cycloalkyl ring fragmentations.

The structures of isobaric, but potentially isomeric ions produced from different precursors (such as [M $\mathrm{A}]^{+}$or $\left[\mathrm{M}-\mathrm{R}^{\prime}\right]^{+}$ions formed from compounds which only differ from each other by $\mathrm{R}$ or $\mathrm{R}^{\prime}$, respectively) were probed by studying their MIKE spectra. In most cases, such ions produced nearly identical MIKE spectra indicating that they either possessed identical structures immediately upon their formation or must have rearranged to a common structure prior to further decompositions in the second field-free region (2FFR). Some representative examples are listed in Table 3.

The tetracyano derivatives 1-4 presented a good opportunity to study the effect of the cycloalkyl ring size on the exo/endo ratios in the gas phase. Some trends can be seen from Table 1a. Thus, the $[\mathrm{M}-\mathrm{CN}]^{+}$ abundances are decreasing, and $[\mathrm{M}-\mathrm{A}]^{+}$(attributed to the endo form) are increasing with the cycloalkyl ring size. This is in agreement with the NMR analysis of 
Table 3. Characteristic decompositions in the second field-free region (MIKE spectra) of selected fragment ions produced from 1-17 by electron ionization. In all the four pairs, ions having the same elemental composition produced nearly identical MIKE spectra

\begin{tabular}{|c|c|c|c|c|c|c|}
\hline Compound & $\mathrm{n}$ & $\mathrm{R}$ & $\mathrm{R}^{\prime}$ & Ion composition & lon type & Further losses in the $2 \mathrm{FFR}$ \\
\hline 13 & 1 & COOEt & coOMe & $\mathrm{C}_{12} \mathrm{H}_{9} \mathrm{~N}_{2} \mathrm{OS}$ & {$[\mathrm{M}-\mathrm{MeOH}-\mathrm{COOEt}]^{+}$} & $\mathrm{HCN}, \mathrm{MeS}$ \\
\hline 16 & 1 & coOMe & COOEt & $\mathrm{C}_{12} \mathrm{H}_{9} \mathrm{~N}_{2} \mathrm{OS}$ & {$[\mathrm{M}-\mathrm{EtOH}-\mathrm{COOMe}]^{+}$} & $\mathrm{HCN}, \mathrm{MeS}^{\circ}$ \\
\hline 2 & 2 & $\mathrm{CN}$ & $\mathrm{CN}$ & $\mathrm{C}_{13} \mathrm{H}_{12} \mathrm{~N}_{3} \mathrm{~S}$ & {$[\mathrm{M}-\mathrm{CN}]^{+}$} & $\mathrm{Me}, \mathrm{MeS}$ \\
\hline 5 & 2 & COOMe & $\mathrm{CN}$ & $\mathrm{C}_{13} \mathrm{H}_{12} \mathrm{~N}_{3} \mathrm{~S}$ & {$\left[\mathrm{M}-\mathrm{COOMe}^{+}\right.$} & $\mathrm{Me}, \mathrm{MeS}$ \\
\hline 3 & 3 & $\mathrm{CN}$ & $\mathrm{CN}$ & $\mathrm{C}_{12} \mathrm{H}_{13} \mathrm{~N}_{2} \mathrm{~S}$ & {$[\mathrm{M}-\mathrm{A}]^{+}$} & Mes \\
\hline 9 & 3 & COOEt & $\mathrm{CN}$ & $\mathrm{C}_{12} \mathrm{H}_{13} \mathrm{~N}_{2} \mathrm{~S}$ & {$[\mathrm{M}-\mathrm{A}]^{+}$} & MeS \\
\hline 6 & 4 & COOMe & $\mathrm{CN}$ & $\mathrm{C}_{15} \mathrm{H}_{12} \mathrm{~N}_{3} \mathrm{O}$ & {$[\mathrm{M}-\mathrm{MeS}-\mathrm{MeOH}]^{+}$} & $\mathrm{CN} ; \mathrm{HCN}$ \\
\hline 10 & 4 & COOEt & $\mathrm{CN}$ & $\mathrm{C}_{15} \mathrm{H}_{12} \mathrm{~N}_{3} \mathrm{O}$ & {$[\mathrm{M}-\mathrm{MeS}-\mathrm{EtOH}]^{+}$} & $\mathrm{CN} ; \mathrm{HCN}$ \\
\hline
\end{tabular}

5-17, which showed that the endo structures are strongly preferred in the compounds containing sevenand eight-membered rings. The fact that the endo forms were not observed at all in the NMR spectra of Compounds 1-4 may reflect the influence of the intermolecular interactions and solvent effects in the condensed phase, which are absent under mass-spectrometric conditions. Note that the relative abundance of $[\mathrm{M}-\mathrm{A}]^{+}$ ions (Table $1 \mathrm{a}-\mathrm{c}$ ) changes from $40-100 \%$ in the spectra of the predominantly endo (by the NMR evidence) compounds down to $0-20 \%$ in the spectra of Compounds 1-4. The very presence of $[\mathrm{M}-\mathrm{A}]^{+}$ions in the spectra of 1-4 can be interpreted in two ways. Either there occur hydrogen shifts and rearrangements in the exo form of the $\mathrm{M}^{+\cdot}$ similar to those described in [5] or a small fraction of the $\mathrm{M}^{+\cdot}$ ions exists in the endo form. Since it is not obvious why a hydrogen shift should occur exclusively to a $=\mathrm{C}(\mathrm{CN})_{2}$ group in 1-4 but not to $=\mathrm{C}(\mathrm{CN}) \mathrm{R}$ or $=\mathrm{CR}^{\prime} \mathrm{R}^{\prime \prime}$ groups in $\mathbf{5}-\mathbf{1 7}$, although the electron-withdrawing properties of the $\mathrm{R}$ and $\mathrm{CN}$ substituents are close, we prefer the latter explanation.

\section{Conclusions}

The mass-spectrometric study generally confirmed the available data on the exo/endo isomerism of the double bond in Compounds 1-17. Those bearing one ester group ( $\mathrm{R}^{\prime}$ ) or two ( $\mathrm{R}$ and $\mathrm{R}^{\prime}$ ) exist as pure endo isomers both in solution and in the gas phase. The exo form is strongly preferred in the tetracyano derivatives, although traces of the endo form were detected in their mass spectra based on the diagnostic $[\mathrm{M}-\mathrm{RCHCN}]^{+}$ ions. Apart from the substitution pattern, the share of the endo form generally increases with the cycloalkyl ring size both in solution and in the gas phase. The mass spectra do not present evidence for any extensive hydrogen shifts or hydrogenation of the cyanomethylene group prior to ionization, except possibly in the case of Compounds 1-4.

This study suggests that mass-spectrometric investigations may advantageously complement structural investigations carried out in solution by means of NMR spectroscopy. The detection of minor amounts of the exo form in the mass spectra of tetracyano derivatives possibly illustrates the effect of the medium on the double-bond isomerism.

\section{References}

1. Woller, J. Ph.D. Thesis. Potsdam University: Germany, 1996.

2. Kleinpeter, E.; Heydenreich, M.; Woller, J.; Wolf, G.; Koch, A.; Kempter, G.; Pihlaja, K. Configuration and Stereodynamics of Exo/Endo-Isomeric Push-Pull Alkenes of Pentadiene Structure. J. Chem. Soc. Perkin Trans. 1998, 2, 1877-1888.

3. Ferrari, C.; Kleinpeter, E.; Taddei, F. A Theoretical Ab Initio MO Investigation on the Relative Stability of Exo/Endo Isomers of Substituted Cycloalkanes-Cycloalkenes. J. Mol. Struct. (THEOCHEM) 2001, 548, 93-105.

4. Spencer, G. F.; Daxenbichler, M. E. Gas ChromatographyMass Spectrometry of Nitriles, Isothiocyanates, and Oxazolidinethiones Derived from Crusifereous Glucosinolates. J. Sci. Food Agric. 1980, 31, 359-367.

5. Wang, C.-B.; Her, G.-R.; Watson, J. T. Mass Spectra of Dicyanomethylene Derivatives of Benzophenone Analogs. Org. Mass Spectrom. 1983, 18, 457-461.

6. Her, G.-R.; Dolnikowski, G. G.; Watson, J. T. Hydrogen Radical/Molecule Reactions in the Negative Ion Mass Spectrometry of Dicyanomethane Derivatives of 9-Fluorenone and Benzophenone. Org. Mass Spectrom. 1986, 21, 329-334.

7. Mermilliod, N.; Sellier, N. Mass Spectrometry of $7,7^{\prime}, 8,8^{\prime}-$ Tetracyanoquinodimethane and Some of Its Radical Anion Salts. Org. Mass Spectrom. 1984, 19, 563-568.

8. Tominaga, Y.; Matsuoka, Y.; Oniyama, Y.; Uchimura, Y.; Komiya, H.; Hirayama, M.; Kohra, S.; Hosomi, A. Polarized Ethylenes. IV. Synthesis of Polarized Ethylenes Using Thioamides and Methyl Dithiocarboxylates and Their Applications to Syntheses of Pyrazoles, Pyrimidines, Pyrazolo[3,4- $d$ ] pyrimidines, and 5-Aza[2.2.3]cyclazines. J. Heterocycl. Chem. 1990, 27, 647-660.

9. Hartke, K.; Radau, S. 3H-Pyrrolizine und Azapentalene. Liebigs Ann. Chem. 1974, 2110-2123.

10. Sobenina, L. N.; Mikhaleva, A. I.; Sergeeva, M. P.; Petrova, O. V.; Aksamentova, N.; Kozyreva, O. B.; Toryashinova, D.-S. D.; Trofimov, B. A. Pyrrole-2-dithiocarboxylates: Synthesis of 2-(1-alkylthio-2-cyanoethenyl)pyrroles. Tetrahedron 1995, $51,4223-4230$. 